\title{
Lettre à la rédaction : Évolution de la réglementation française relative au Cannabis
}

\section{Letter to the editor: \\ Evolution of the French regulation relating to the Cannabis}

Gilbert FOURNIER

Laboratoire de Pharmacognosie, UMR 8076, CNRS (BioCIS), Faculté de Pharmacie, 5, rue J.-B. Clément F-92290 CHÂTENAY-MALABRY

Tél : 0146835597 - Fax : 0146835710 - E-mail : gilbert.fournier@cep.u-psud.fr

Dans un article récemment publié, avait été rappelée la réglementation relative au chanvre (Cannabis sativa L.) (1). L'attention avait notamment été attirée sur le fait que coexistent deux séries de textes : des articles du Code de la Santé publique (CSP) français et des règlements parus au Journal officiel des Communautés euro- péennes. Entre ces textes, il existe trois différences principales, données dans le tableau I.

Dans ce même article, il avait été mentionné qu'une harmonisation était en cours. Cela est chose faite depuis la parution au Journal officiel de la République française de l'arrêté du 24 février 2004 modifiant l'ar-

Tableau I : Réglementation relative du chanvre. Différences entre le CSP et le JOCE.

\begin{tabular}{|l|c|c|}
\hline & $\begin{array}{c}\text { Code de la Santé Publique } \\
\text { Français }\end{array}$ & $\begin{array}{c}\text { Journal Officiel des } \\
\text { Communautés Européennes }\end{array}$ \\
\hline $\begin{array}{l}\text { teneur maximale en delta-9- } \\
\text { tétrahydrocannabinol des } \\
\text { variétés de cannabis }\end{array}$ & $\leq 0,3 \%$ & $\leq 0,2 \%$ \\
\hline $\begin{array}{l}\text { Nombre de variétés et champ } \\
\text { d'application }\end{array}$ & $\begin{array}{c}18 \text { variétés } \\
\text { autorisées à la culture }\end{array}$ & $\begin{array}{c}26 \text { variétés } \\
\text { pouvant bénéficier de } \\
\text { paiements à la surface }\end{array}$ \\
\hline $\begin{array}{l}\text { Méthode de dosage du delta- } \\
\text { 9-tétrahydrocannabinol }\end{array}$ & $\begin{array}{c}\text { Chromatographie en Phase Gazeuse } \\
\text { avec colonne remplie }\end{array}$ & $\begin{array}{c}\text { Chromatographie en Phase Gazeuse } \\
\text { avec colonne capillaire }\end{array}$ \\
\hline
\end{tabular}


rêté du 22 août 1990 portant application de l'article $\mathrm{R}$. 5181 du code de la santé publique pour le cannabis (2).

Dans ce nouveau texte, il est précisé que «sont autorisées la culture, l'importation, l'exportation et l'utilisation industrielle et commerciale (fibres et graines) des variétés de Cannabis sativa $\mathrm{L}$. répondant aux critères suivant :

- la teneur en delta-9-tétrahydrocannabinol de ces variétés n'est pas supérieure à $0,2 \%$;

- la détermination de la teneur en delta-9-tétrahydrocannabinol et la prise d'échantillons en vue de cette détermination sont effectuées selon la méthode communautaire prévue en annexe» [texte identique au règlement (CE) $n^{\circ} 2860 / 2000$ de la Commission du 27 décembre 2000 paru au Journal officiel de Communautés européennes le 28.12.2000 (3)].

Par ailleurs, la liste des variétés dont la culture est autorisée en France est complétée par l'adjonction de la variété Santhica 27 . Cette nouvelle variété présente l'intérêt de ne pas renfermer de delta-9-tétrahydrocannabinol (4).

\section{Conclusion}

Les réglementations française et européenne sont désormais quasiment identiques. En effet, même si dans les deux cas, le taux maximal autorisé est fixé à $0,2 \%$, le champ d'application reste différent puisque pour le CSP ce taux concerne l'autorisation de cultiver une variété en France, alors que la réglementation européenne ne s'applique que pour l'octroi d'une subvention lors de la culture. Par ailleurs, en 2004 et au regard de la réglementation en vigueur, dix variétés ne devraient pas pouvoir être cultivées en France alors que leur production peut être subventionnée par de la Communauté européenne ; il s'agit des variétés Beniko, Bialobrzeskie, Chamaeleon, Fasamo, Fibrico TC; Finola, Juso 14, Red Petiole, Uniko B et Uso 31.

Quant à la modification de la méthode d'analyse, il s'agit simplement de la prise en compte des avancées technologiques en la matière. Il convient cependant de rappeler que dans l'annexe sont également décrites les conditions d'échantillonnage et que celles-ci ont précédemment fait l'objet d'une étude critique (1).

\section{Références}

1. Fournier G., Beherec O., Bertucelli S., Mathieu J.P. A propos des conditions d'échantillonnage pour le dosage du delta-9-tétrahydrocannabinol dans les variétés de chanvre à usage industriel. Ann. Toxicol. Anal. 2001 ; $13: 275-81$.

2. Journal officiel de la République française - Arrêté du 24 février 2004 modifiant l'arrêté du 22 août 1990 portant application de l'article R. 5181 du code de la santé publique pour le cannabis. J.O. du 21 mars 2004, p. 55085509.

3. Journal officiel des Communautés européennes Règlement (CE) $n^{\circ} 2860 / 2000$ de la Commission du 27 décembre 2000 modifiant le règlement (CE) $\mathrm{n}^{\circ}$ $2316 / 1999$ portant modalités d'application du règlement (CE) $n^{\circ} 1251 / 1999$ du Conseil instituant un régime de soutien aux producteurs de certaines cultures arables pour y inclure le lin et le chanvre destinés à la production de fibres, préciser les règles concernant les superficies gelées et modifier les superficies de base pour la Grèce et le Portugal.

4. Fournier G., Richez-Dumanois C., Duvezin J., Mathieu J.P., Paris M. Identification of a New Chemotype in Cannabis sativa : Cannabigerol-Dominant Plants, Biogenetic and Agronomic Prospects. Planta Med. 1987 ; 53(3) : 277-80. 